\title{
Knowledge of Anaesthesia Providers on Exposure to Inhalational Anaesthetic Agents in Ghana
}

\author{
Ebenezer Owusu Darkwa1 ${ }^{*}$, Robert Djagbletey1, Ernest Ofosu-Appiah¹, Christian Owoo1, \\ Daniel A. Y. Sottie'2, Raymond Essuman', George Aryee ${ }^{1}$ \\ ${ }^{1}$ Department of Anaesthesia, School of Medicine and Dentistry, College of Health Sciences, University of Ghana, Accra, Ghana \\ ${ }^{2}$ Department of Anaesthesia, Korle-Bu Teaching Hospital, Accra, Ghana \\ Email: *eoddarquah@yahoo.co.uk
}

How to cite this paper: Darkwa, E.O., Djagbletey, R., Ofosu-Appiah, E., Owoo, C., Sottie, D.A.Y., Essuman, R. and Aryee, G. (2017) Knowledge of Anaesthesia Providers on Exposure to Inhalational Anaesthetic Agents in Ghana. Journal of Biosciences and Medicines, 5, 21-34.

https://doi.org/10.4236/jbm.2017.54003

Received: March 21, 2017

Accepted: April 25, 2017

Published: April 30, 2017

Copyright (c) 2017 by authors and Scientific Research Publishing Inc. This work is licensed under the Creative Commons Attribution International License (CC BY 4.0).

http://creativecommons.org/licenses/by/4.0/

cC) (i) Open Access

\begin{abstract}
Background: Chronic exposure to inhaled anaesthetic agents poses an occupational hazard related to the practice of anaesthesia. Therefore, this study sought to find out the perception of anaesthesia providers on exposure to inhalational anaesthetics, evaluate their knowledge on the effects of chronic exposure and strategies to reduce chronic exposure to operating room inhalational anaesthetic agents. Method: This cross-sectional survey was conducted by administering a self-administered questionnaire to 71 anaesthesia providers in Ghana who attended the annual refresher course of the faculty of Anaesthesia, West African College of Surgeons, in 2016. Data collected were analysed and presented as frequencies and percentages. Results: Halothane and isoflurane were the most frequently used inhalational agents by the respondents. Majority (90.1\%) of the respondents perceived they are exposed to inhalational anaesthetics in their working environment. Majority of the anaesthetic providers cited poorly functioning scavenging systems $(28.2 \%)$ and use of paediatric Ayre's T-piece (28.2\%) as sources of exposure to inhalational anaesthetics. All respondents admitted making attempts to reduce their exposure to inhalational anaesthetics. Majority of the respondents mentioned teratogenicity $(77.5 \%)$ and hepatotoxicity $(67.6 \%)$ as effects of chronic exposure to inhaled anaesthetic agents. Conclusion: Anaesthesia providers in Ghana perceived they are chronically exposed to inhalational anaesthetic agents in their work environment. They are aware of the sources of inhalational anaesthetic agent exposure, associated health risks and strategies required to reduce chronic exposure to inhaled anaesthetic agents.
\end{abstract}

\section{Keywords}

Inhalational Anaesthetic Agents, Anaesthesiologist, Knowledge, Perception, 
Exposure

\section{Introduction}

Inhalational anaesthetic agents enter the body via the lungs and are distributed by the blood into different tissues. The brain is the target organ for inhalational anaesthetic agents. They work by amplifying inhibitory function or decreasing excitatory transmission of nerve endings in the brain. Chronic exposure to high concentrations of inhalational anaesthetic agents has been reported to affect health [1] [2] [3] [4] [5].

William T.G. Morton in 1846 demonstrated the anaesthetic effects of diethyl ether which became an important landmark in medical practice. Soon after, other inhaled anaesthetic agents such as nitrous oxide, chloroform, cyclopropane and trichloroethylene and series of halogenated anaesthetics (enflurane, halothane, isoflurane, sevoflurane and desflurane) were introduced. The dangers of inhaled anaesthetic agents to the patient and the anaesthesia providers have long been postulated. In 1967, studies showed a high incidence of headache, nausea, irritability, fatigue and adverse reproductive effects among anaesthesia providers using inhaled anaesthetics [6] [7]. These studies inspired other researches on effects of inhaled anaesthetics which led to the publishing of the booklet "Waste anaesthetic gases in operating room air: a suggested program to reduce personnel exposure" by American Society of Anesthesiologists (ASA) in 1981 [8].

The first report in the 1970s on deteriorating psychomotor performance of the operating room personnel following chronic exposure to nitrous oxide and halothane, [1] led to active studies in this area. Most of these studies showed an increase in frequency of symptoms such as headaches, dizziness, memory impairment, fatigue, deterioration of reaction time, and poor after work performance test and central imbalance in operating room personnel exposed chronically to inhalational anaesthetics [2] [3] [4] [5]. However, a subsequent multicentre study suggested the absence of the above symptoms in operating room personnel so long as their exposed working environment inhalational anaesthetic concentrations are kept below the recommended levels by applying appropriate protective measures [9].

Numerous animal studies have been conducted on the carcinogenic and genotoxic effects of inhalational anaesthetic agents but these have failed to prove malignant abnormalities in histological samples as a result of delayed consequence of exposure [10]-[16]. Some studies have shown that the older inhalational agents are potentially carcinogenic whilst the newer inhalational agents are not [11] [17].

Various animal studies have shown contradictory results concerning the hepatotoxic effects of inhaled anaesthetic agents [18] [19]. Halothane hepatitis has been demonstrated in recurrent exposure to halothane, however there is a 
limited report on induced hepatitis caused by other halogenated agents [20] [21]. It has also been noted that health workers exposed to inhaled anaesthetic gases have elevated serum bilirubin and liver enzymes [22].

Earlier studies have reported an association between inhaled anaesthetic gas exposure and foetal anomalies (teratogenic effects) and miscarriages/fertility problems [17] [19] [23]-[31]. However, these studies have been criticised on account of their reproducibility in human subjects [17] [30] [31] [32] [33] [34].

Several researches involving laboratorial exams of operating room personnel seems to favour the possibility that working in operating rooms poses an occupational risk such as chronic exposure to inhalational anaesthetic agents [23] [32] [35]-[41].

Despite negative reports on the effects of inhaled anaesthetic gases, the issue is still surrounded by controversies. Considering the variability of individual responses to different inhalational anaesthetic agents, contradictory results are found in literature. The decisive factors that appear to influence the adverse health effects of exposure to anaesthetic gases are mainly the type of gases used, the length of exposure, and the gas concentrations [42].

An alert from the United States Government's National Institute of Occupational Safety and Health advocates action to dispel any complacency and cites reports which suggest that health care workers may be at risk even when operating theatres are provided with scavenging equipment [43]. This confirms similar findings in studies of operating theatres in Britain, in which half the personal samples from anaesthetists exceeded an average concentration of nitrous oxide of $100 \mathrm{ppm}$ during the period monitored [44]. The alert from the National Institute of Occupational Safety and Health emphasises that simply installing a ventilation system and scavenging equipment is not enough. Such technology must be supported by planned preventive maintenance, regular inspections for leaks and defective equipment, and good anaesthetic technique. This should be supported by a commitment to training so that all concerned understand the preventive measures required. This survey therefore sought to find out the perception of anaesthesia providers on exposure to inhalational anaesthetics, evaluate their knowledge on the effects of chronic exposure and strategies to reduce chronic exposure to operating room inhalational anaesthetic agents.

\section{Methods}

A cross-sectional survey was conducted among all qualified and certified anaesthesia providers in Ghana who attended the annual refresher course of the faculty of anaesthesia, West African College of Surgeons using a structured questionnaire with both open-ended and closed questions with multiple options designed by the researchers. This conference was held at the Korle-Bu Teaching Hospital in Accra from 29th February to 3rd March, 2016. Seventy-one (71) qualified anaesthesia providers (50 Anaesthesiologists and 21 Nurse Anaesthetists) working in various tertiary and non-tertiary, public and private hospitals attended this refresher course themed "Principles and Practice of Anaesthesia" 
and were all enrolled into the survey. Seventy-one (71) questionnaires were distributed with 71 respondents. The questionnaire used for the study outlined the perception of the anaesthesia providers on exposure to inhaled anaesthetics, their knowledge on effects of exposure and strategies to reduce anaesthetic gas exposure.

The questionnaire (Appendix) was developed by a team of anaesthetists and a biostatistician. It was pre-tested at the Department of Anaesthesia of the Korle$\mathrm{Bu}$ Teaching Hospital on randomly selected 5 Anaesthesiologists and 5 Nurse Anaesthetists.

Permission for the survey was obtained from the organisers of the conference and consent was also obtained from the anaesthesia providers that participated in the survey. Data was entered into Microsoft ${ }^{\circledR}$ Access Database 2013, analysed using Microsoft ${ }^{\circledR}$ Excel 2013 and presented as frequencies and percentages.

\section{Results}

In this survey, $50(70.4 \%)$ of the respondents were Anaesthesiologists and 21 (29.6\%) were Nurse Anaesthetists. Majority of the respondents were females. More than half of the respondents have practiced anaesthesia for less than five years (Table 1).

\subsection{Use of Inhalational Anaesthetic Agents}

Out of seventy-one (71) anaesthesia providers, only $1(1.4 \%)$ did not use inhalational anaesthetics in their practice. Sixty-five (91.5\%) uses halothane, 67 (94.4\%) uses isoflurane, 35 (49.3\%) uses sevoflurane, 11 (15.5\%) uses nitrous oxide whilst 1 (1.4\%) uses desflurane in their practice.

\subsection{Perception of Exposure to Inhalational Anaesthetic Agents}

Sixty-four (90.1\%) perceived to be exposed to inhalational anaesthetics in their working environment. However, only 29 (40.8\%) acknowledged an allowable limit to the concentration of inhalational anaesthetics in their working environment.

Table 1. Demographic characteristics.

\begin{tabular}{ccc}
\hline Demographic Characteristics & Frequency (n) & Percentage (\%) \\
\hline Anaesthesia Provider & 50 & 70.4 \\
Anaesthesiologist & 21 & 29.6 \\
Nurse Anaesthetist & & \\
Gender & 33 & 46.5 \\
Male & 38 & 53.5 \\
Female & & \\
Years of Practice & 40 & 56.3 \\
$<5$ & 12 & 16.9 \\
$5-10$ & 19 & 28.6 \\
$>10$ & &
\end{tabular}


Majority of the anaesthesia providers cited poorly functioning scavenging systems 20 (28.2\%) and use of paediatric Ayre's T-piece 20 (28.2\%) as perceived reasons of exposure to inhalational agents (Table 2). Other reasons alluded to were leakage from anaesthetic machines and circuits, improper fitting face mask, and use of high flows during anaesthesia.

The few anaesthesia providers 7 (9.9\%) who did not perceive to be exposed to inhalational agents said they either have properly functioning scavenging system or performed only regional anaesthesia (Table 3). One provider however did not have any reason for his perceived non-exposure.

\subsection{Knowledge on Effects of Exposure}

Majority of the anaesthesia providers identified tiredness (87.3\%) and headaches (70.4\%) as symptoms of chronic exposure to inhalational agents as shown in Table 4.

Majority of anaesthetic providers were also aware of the major organ effects of chronic exposure to inhaled anaesthetics: teratogenicity (77.5\%) and liver disorders $(67.6 \%)$. Only few were aware that chronic exposure to inhaled anaesthetics could cause allergic reaction, neurologic disorders and bone marrow suppression as depicted in Table 5.

Table 2. Perceived reasons of exposure to inhalational anaesthetic agents.

\begin{tabular}{cc}
\hline Reasons & Frequency (\%) \\
\hline Poorly functioning scavenging system & $20(28.2 \%)$ \\
Use of paediatric Ayres T-Piece & $20(28.2 \%)$ \\
Leakage from breathing circuit & $17(24.0 \%)$ \\
Leakage from anaesthetic machine & $15(21.1 \%)$ \\
Lack of scavenging system & $13(18.3 \%)$ \\
Improper fitting facemask & $7(9.8 \%)$ \\
High flow anaesthesia & $1(1.4 \%)$ \\
\hline
\end{tabular}

Table 3. Reasons for perceived non-exposure to inhalational anaesthetic agents.

\begin{tabular}{cc}
\hline Reasons & Frequency (\%) \\
\hline Presence of properly functioning scavenging system & $5(7 \%)$ \\
Does only regional anaesthetic cases & $1(1.4 \%)$ \\
No reason & $1(1.4 \%)$ \\
\hline
\end{tabular}

Table 4. Knowledge on symptoms of chronic exposure to inhalational anaesthetic agents.

\begin{tabular}{cc}
\hline Symptoms & Percentage (\%) \\
\hline Tiredness & 87.3 \\
Headache & 70.4 \\
Irritability & 35.2 \\
Nausea & 26.8 \\
Memory disorder & 19.7 \\
\hline
\end{tabular}




\subsection{Knowledge on Strategies to Reduce Exposure to Inhaled Anaesthetics}

None of the anaesthesia providers admitted to a routine monitoring of inhalational anaesthetics in their working environment.

All $71(100 \%)$ anaesthesia providers admitted making attempts to reduce their exposure to inhalational anaesthetics.

All anaesthesia providers mentioned that ensuring a properly functioning scavenging was a strategy in reducing exposure to inhalational anaesthetics. Other strategies suggested included use of regional anaesthesia techniques, use of total intravenous anaesthesia (TIVA) and use of circle system as shown in Table 6.

\section{Discussion}

From this survey, halothane, isoflurane and sevoflurane were the commonest inhalational anaesthetic agents used in clinical practice in Ghana. However, isoflurane (94.4\%) and halothane (91.5\%) usage were very high as noted in other studies [45]. Halothane, however, is reported to be rarely used in the united states currently [46]. Halothane and isoflurane are less costly compared to sevoflurane and desflurane [47] and therefore may explain the commonest usage of these inhalational agents in a developing country like Ghana. Secondly, most hospitals do not have compatible sevoflurane vapourisers which shows its reduced use. Desflurane usage was the least common inhalational anaesthetic re-

Table 5. Knowledge of effect of inhalational anaesthetic agents on major organ function.

\begin{tabular}{cc}
\hline Effects & Frequency (\%) \\
\hline Teratogenicity & $55(77.5 \%)$ \\
Liver disorders & $48(67.6 \%)$ \\
Renal disorders & $24(33.8 \%)$ \\
Carcinogenicity & $21(29.6 \%)$ \\
Allergic reaction & $5(7.0 \%)$ \\
Fertility problems & $4(5.6 \%)$ \\
Neurological disorders & $2(2.8 \%)$ \\
Bone marrow suppression & $1(1.4 \%)$ \\
\hline
\end{tabular}

Table 6. Strategies for reducing exposure to inhalational anaesthetic agents.

\begin{tabular}{cc}
\hline Strategies & Frequency (\%) \\
\hline Ensuring properly functioning scavenging system & $71(100 \%)$ \\
Use of regional anaesthetic techniques & $68(95.8 \%)$ \\
Use of total intravenous anaesthesia (TIVA) & $59(83.1 \%)$ \\
Use of circle system & $52(73.2 \%)$ \\
Ensuring properly functioning air conditioners in theatres & $17(23.9 \%)$ \\
Use of tight fitting facemask/avoiding use of paediatric Ayres T-piece & $12(16.9 \%)$ \\
Use of low fresh gas flow during anaesthesia & $5(7.0 \%)$
\end{tabular}


ported by the anaesthesia providers (1.4\%). Other studies however reported desflurane as one of the commonest inhalational anaesthetics in use [46] [48]. These studies were however in developed countries. Nitrous oxide has favourable properties noted in literature [49] [50], however, it has potential side effects as well [51] and this may explain its low usage (15.5\%) among the anaesthesia providers studied. There is the added disadvantage of production, distribution and relative cost of nitrous oxide in the sub-region especially Ghana.

There was an observed high level of perceived exposure to inhalational anaesthetic agents among anaesthesia providers in their working environment (90.1\%). Such high perception of exposure to inhalational anaesthetics have also been reported in other studies [45] [52]. Absent scavenging systems (18.3\%) as well as improperly functioning scavenging systems (28.2\%) were cited by anaesthesia providers in this study as sources of operating theatre pollution agreeing with the reports of other studies [53] [54] [55] [56] [57]. Potential leakages of inhaled anaesthetic agents from the paediatric Ayre's T-piece (28.2\%), breathing circuits (24\%) and anaesthetic machines (21.1\%) were also mentioned as sources of operating theatre pollution and therefore exposure of anaesthesia providers to inhalational anaesthetics. This observation agrees with reports of previous studies [48] [58]. Anaesthesia providers in the study setting also believe that leakages from improperly fitting facemasks (9.8\%) is a source of chronic exposure to inhaled anaesthetics confirming the findings of other studies [35] [53].

Anaesthesia providers from this survey reported tiredness, headache, nausea, irritability and memory disorders as symptoms of chronic exposure to inhalational anaesthetics (Table 4). This agrees with reports of previous studies [2] [3] [4] [5] [59].

The anaesthesia providers under study were well aware of some of the major organ effects of chronic exposure to inhalational anaesthetic agents. Teratogenicity, liver disorders, renal disorders and carcinogenicity were among the highest mentioned organ damage effects of inhalational anaesthetics. This well agrees with documented literature [12] [17] [30].

All the anaesthesia providers in this survey reported taking precautions in an attempt to reduce their exposure to inhalational anaesthetics. Various strategies were mentioned by the providers as a means of preventing exposure (Table 6). All the anaesthesia providers asserted that properly functioning scavenging system can prevent accumulation of inhalational anaesthetic agents in theatres and therefore reduce anaesthetic gas exposure as reported by other studies [35]. Another effective means of prevention of exposure to inhalational anaesthetics was avoidance of anaesthetic techniques that cause accumulation of inhalational anaesthetics in operating theatres [35] [57]. From this survey, total intravenous anaesthesia (83.1\%), regional anaesthesia (95.8\%), and avoidance of use of paediatric Ayre's T-piece (16.9\%) and use of circle system (73.2\%) were mentioned as some of the techniques of preventing exposure to inhalational anaesthetic agents. Avoidance of high fresh gas flows was categorically mentioned by Ryan and Nielsen as a measure of reducing exposure to inhalational anaesthetics in 
operating theatres [60] [61]. Seven percent (7\%) of anaesthesia providers in this survey mentioned the use of low fresh gas flows as a strategy of preventing exposure to inhalational anaesthetics. An effective room air conditioning system in operating theatre reduces anaesthetic gas exposure [58], as noted by $23.9 \%$ of anaesthesia providers in this survey.

The survey was conducted among anaesthesia providers in Ghana. Findings may vary with the geographic location, anaesthetics and facilities available to anaesthesia providers surveyed and presence or otherwise of policies and regulatory framework for monitoring anaesthetic gas exposure. The findings of this study can therefore not be generalized globally. Furthermore, the questionnaire may not have been rigorously developed to ensure reliability and reproducibility.

\section{Conclusion}

Anaesthesia providers have a responsibility to be cognizant of the risks within their working environment and the need for reducing operating room anaesthetic pollution. The findings of this study reveal that anaesthesia providers in Ghana are aware of the risk and sources of anaesthetic gas exposure and strategies of reducing exposure to inhaled anaesthetics. It is therefore important for various health facilities to have an effective maintenance program that regularly checks and services all anaesthetic equipment including scavenging systems. Continuous education on sources and risk of anaesthetic gas exposure as well as adoption of strategies aimed at reducing anaesthetic gas exposure and provision of a safe working environment for the anaesthetists is important.

\section{Acknowledgements}

The authors wish to thank the organisers of the 2016 edition of the West African College of Surgeons Faculty of Anaesthesia refresher course. We also thank all the anaesthesia providers who attended the refresher course and participated in the study.

\section{References}

[1] Bruce, D., Bach, M. and Arbit, J. (1974) Trace Anesthetic Effects on Perceptual, Cognitive, and Motor Skills. Anesthesiology, 40, 453-457.

https://doi.org/10.1097/00000542-197405000-00010

[2] Saurel-Cubizolles, M., Estryn-Behar, M., Maillard, M., Mugnier, N., Masson, A. and Monod, G. (1992) Neuropsychological Symptoms and Occupational Exposure to Anaesthetics. Occupational and Environmental Medicine, 49, 276-281. https://doi.org/10.1136/oem.49.4.276

[3] Lucchini, R., Toffoletto, F., Camerino, D., et al. (1995) Neurobehavioral Functions in Operating Theatre Personnel Exposed to Anesthetic Gases. La Medicina del Lavoro, 86,27

[4] Lucchini, R., Placidi, D., Toffoletto, F. and Alessio, L. (1996) Neurotoxicity in Operating Room Personnel Working with Gaseous and Nongaseous Anesthesia. In ternational Archives of Occupational and Environmental Health, 68, 188-192. https://doi.org/10.1007/BF00381630 
[5] Vouriot, A., Gauchard, G.C., Chau, N., Nadif, R., Mur, J.-M. and Perrin, P.P. (2005) Chronic Exposure to Anesthetic Gases Affects Balance Control in Operating Room Personnel. Neurotoxicology, 26, 193-198.

[6] Vaĭsman, A. (1967) Working Conditions in the Operating Room and Their Effect on the Health of Anesthetists. EksperimentaP naia Khirurgiia i Anesteziologiia, 12, 44.

[7] Fink, B., Shepard, T. and Blandau, R. (1967) Teratogenic Activity of Nitrous Oxide. Nature, 214, 146-148. https://doi.org/10.1038/214146a0

[8] American Society of Anesthesiologists (1981) Waste Anesthetic Gases in Operating Room Air: A Suggested Program to Reduce Personnel Exposure. American Society of Anesthesiologists, Park Ridge, IL.

[9] Lucchini, R., Belotti, L., Cassitto, M., et al. (1997) Neurobehavioral Functions in Operating Theatre Personnel: A Multicenter Study. La Medicina del Lavoro, 88, 396.

[10] Coate, W.B., Ulland, B.M. and Lewis, T.R. (1979) Chronic Exposure to Low Concentrations of Halothane-Nitrous Oxide: Lack of Carcinogenic Effect in the Rat. Anesthesiology, 50, 306-309. https://doi.org/10.1097/00000542-197904000-00005

[11] Edmond, I., Eger, I., White, A.E., Brown, C.L., Biava, C.G., Corbett, T.H. and Stevens, W.C. (1978) A Test of the Carcinogenicity of Enflurane, Isoflurane, Halothane, Methoxyflurane, and Nitrous Oxide in Mice. Anesthesia and Analgesia, 57, 678-694.

[12] Pasquini, R., Scassellati-Sforzolini, G., Fatigoni, C., et al. (2001) Sister Chromatid Exchanges and Micronuclei in Lymphocytes of Operating Room Personnel Occupationally Exposed to Enfluorane and Nitrous Oxide. Journal of Environmental Pathology, Toxicology and Oncology, 20, 8 p. https://doi.org/10.1615/JEnvironPatholToxicolOncol.v20.i2.60

[13] Hoerauf, K., Lierz, M., Wiesner, G., et al. (1999) Genetic Damage in Operating Room Personnel Exposed to Isoflurane and Nitrous Oxide. Occupational and Environmental Medicine, 56, 433-437. https://doi.org/10.1136/oem.56.7.433

[14] Wiesner, G., Schiewe-Langgartner, F., Lindner, R. and Gruber, M. (2008) Increased Formation of Sister Chromatid Exchanges, but Not of Micronuclei, in Anaesthetists Exposed to Low Levels of Sevoflurane. Anaesthesia, 63, 861-864. https://doi.org/10.1111/j.1365-2044.2008.05498.x

[15] Rice, S.A. and Fish, K.J. (1994) Reproductive and Developmental Toxicity of Anesthetics in Animals. In: Ebi, K.L., Rice, SA. and Fish, K.J., Eds., Anesthetic Toxicity, Raven Press Ltd., New York, 157-174.

[16] Vieira, E., Austin, J., Moyes, D. and Shawl, R. (1980) Effects of Low Concentrations of Nitrous Oxide on Rat Fetuses. Anesthesia and Analgesia, 59, 175-177. https://doi.org/10.1213/00000539-198003000-00002

[17] Baden, J.M. and Simmon, V.F. (1980) Mutagenic Effects of Inhalational Anesthetics. Mutation Research, 75, 169-189.

[18] Shingu, K., Eger, E.I., Johnson, B.H., et al. (1983) Hepatic Injury Induced by Anesthetic Agents in Rats. Survey of Anesthesiology, 27, 259.

https://doi.org/10.1097/00132586-198310000-00002

[19] Green, C., Monk, S., Knight, J., Doré, C., Luff, N. and Halsey, M. (1982) Chronic Exposure of Rats to Enflurane 200P.P.M.: No Evidence of Toxicity or Teratogenicity. British Journal of Anaesthesia, 54, 1097-1104.

https://doi.org/10.1093/bja/54.10.1097

[20] Sutherland, D. and Smith, W. (1992) Chemical Hepatitis Associated with Occupa- 
tional Exposure to Halothane in a Research Laboratory. Veterinary and Human Toxicology, 34, 423-424.

[21] Otedo, A. (2004) Halothane Induced Hepatitis: Case Report. East African Medical Journal, 81, 538-539. https://doi.org/10.4314/eamj.v81i10.9238

[22] Casale, T., Caciari, T., Rosati, M.V., et al. (2014) Anesthetic Gases and Occupationally Exposed Workers. Environmental Toxicology and Pharmacology, 37, 267-274. https://doi.org/10.1016/j.etap.2013.12.003

[23] Cohen, E.N., Bellville, J.W. and Brown Jr., B. (1971) Anesthesia, Pregnancy, and Miscarriage: A Study of Operating Room Nurses and Anesthetists. Anesthesiology, 35, 343-347. https://doi.org/10.1097/00000542-197110000-00005

[24] Pharoah, P., Alberman, E., Doyle, P. and Chamberlain, G. (1977) Outcome of Pregnancy among Women in Anaesthetic Practice. The Lancet, 309, 34-36. https://doi.org/10.1016/S0140-6736(77)91666-X

[25] Boivin, J.-F. (1997) Risk of Spontaneous Abortion in Women Occupationally Exposed to Anaesthetic Gases: A Meta-Analysis. Occupational and Environmental Medicine, 54, 541-548. https://doi.org/10.1136/oem.54.8.541

[26] Gauger, V.T., Voepel-Lewis, T., Rubin, P., Kostrzewa, A. and Tait, A.R. (2003) A Survey of Obstetric Complications and Pregnancy Outcomes in Paediatric and Nonpaediatric Anaesthesiologists. Pediatric Anesthesia, 13, 490-495. https://doi.org/10.1046/j.1460-9592.2003.01079.x

[27] Shirangi, A., Fritschi, L. and Holman, C. (2008) Maternal Occupational Exposures and Risk of Spontaneous Abortion in Veterinary Practice. Occupational and Environmental Medicine, 65, 719-725. https://doi.org/10.1136/oem.2007.035246

[28] Shirangi, A., Fritschi, L. and Holman, C.D.A.J. (2009) Associations of Unscavenged Anesthetic Gases and Long Working Hours with Preterm Delivery in Female Veterinarians. Obstetrics and Gynecology, 113, 1008-1017.

https://doi.org/10.1097/AOG.0b013e31819fe996

[29] Teschke, K., Abanto, Z., Arbour, L., et al. (2011) Exposure to Anesthetic Gases and Congenital Anomalies in Offspring of Female Registered Nurses. American Journal of Industrial Medicine, 54, 118-127. https://doi.org/10.1002/ajim.20875

[30] Baden, J. and Kundoma, Y. (1987) Mutagenicity of the Combination of a Volatile Anaesthetic and Nitrous Oxide. British Journal of Anaesthesia, 59, 772-775. https://doi.org/10.1093/bja/59.6.772

[31] Mazze, R.I. (1985) Fertility, Reproduction, and Postnatal Survival in Mice Chronically Exposed to Isoflurane. Anesthesiology, 63, 663-667. https://doi.org/10.1097/00000542-198512000-00017

[32] Buring, J.E., Hennekens, C.H., Mayrent, S.L., Rosner, B., Greenberg, E.R. and Colton, T. (1985) Health Experiences of Operating Room Personnel. Anesthesiology, 62, 325-330. https://doi.org/10.1097/00000542-198503000-00018

[33] Vessey, M. (1978) Epidemiological Studies of the Occupational Hazards of Anaesthesia-A Review. Anaesthesia, 33, 430-438. https://doi.org/10.1111/j.1365-2044.1978.tb12461.x

[34] Ferstandig, L.L. (1978) Trace Concentrations of Anesthetic Gases: A Critical Review of Their Disease Potential. Anesthesia and Analgesia, 57, 328-345. https://doi.org/10.1213/00000539-197805000-00009

[35] (1974) Occupational Disease among Operating Room Personnel: A National Study. Report of an Ad Hoc Committee on the Effect of Trace Anesthetics on the Health of Operating Room Personnel, American Society of Anesthesiologists. Anesthesiology, 41, 321-340. https://doi.org/10.1097/00000542-197410000-00004 
[36] Rosenberg, P. and Kirves, A. (1973) Miscarriages among Operating Theatre Staff. Acta Anaesthesiologica Scandinavica, 53, 37.

[37] Spence, A. and Knill-Jones, R. (1978) Is There a Health Hazard in Anaesthetic Practice? British Journal of Anaesthesia, 50, 713-719.

https://doi.org/10.1093/bja/50.7.713

[38] Tannenbaum, T.N. and Goldberg, R.J. (1985) Exposure to Anesthetic Gases and Reproductive Outcome: A Review of the Epidemiologic Literature. Journal of Occupational and Environmental Medicine, 27, 659-668.

[39] Spence, A. (1987) Environmental Pollution by Inhalation Anaesthetics. British Journal of Anaesthesia, 59, 96-103. https://doi.org/10.1093/bja/59.1.96

[40] Ebi, K.L., Rice, S.A. and Fish, K.J. (1994) Reproductive and Developmental Toxicity of Anesthetics in Humans. In: Ebi, K.L., Rice, S.A. and Fish, K.J., Eds., Anesthetic Toxicity, Raven Press Ltd., New York, 175-198.

[41] Helfenstein, E. (2006) Farmacodinâmica dos anestésicos inalatórios. In: Cangiani, L.M., Posso, I.P., Poterio, G.M.B. and Nogueira, C.S., Eds., Tratado de Anestesiologia, 6th Edition, Atheneu, Sao Paulo, 791-802.

[42] International Section on the Prevention of Occupational Risks in Health Services (2001) Safety in the Use of Anesthetic Gases. International Section on the Prevention of Occupational Risks in Health Services, Hamburg, Germany.

[43] United States Department of Health and Human Services (1994) The National Institute for Occupational Safety and Health: Controlling Exposures to Nitrous Oxide during Anesthetic Administration. The National Institute for Occupational Safety and Health: Department of Health and Human Services, Washington DC, Publication 94-100.

[44] Gray, W. (1989) Occupational Exposure to Nitrous Oxide in Four Hospitals. Anaesthesia, 44, 511-514. https://doi.org/10.1111/j.1365-2044.1989.tb11383.x

[45] Shiraishi, Y. and Ikeda, K. (1990) Uptake and Biotransformation of Sevoflurane in Humans: A Comparative Study of Sevoflurane with Halothane, Enflurane, and Isoflurane. Journal of Clinical Anesthesia, 2, 381-386.

[46] Brown, A., Canosa-Mas, C., Parr, A., Pierce, J. and Wayne, R. (1989) Tropospheric Lifetimes of Halogenated Anaesthetics. Nature, 341, 635-637. https://doi.org/10.1038/341635a0

[47] Varkey, J. (2013) Debunking Volatile Anesthetic Cost Myths between Sevoflurane and Desflurane. Anesthesia eJournal, 1.

[48] Langbein, T., Sonntag, H., Trapp, D., et al. (1999) Volatile Anaesthetics and the Atmosphere: Atmospheric Lifetimes and Atmospheric Effects of Halothane, Enflurane, Isoflurane, Desflurane and Sevoflurane. British Journal of Anaesthesia, 82, 6673. https://doi.org/10.1093/bja/82.1.66

[49] Maloney, W.J. and Maloney, M.P. (2009) Horace Wells and His Significant Contributions to the Discovery of Anesthesia. Journal of the Massachusetts Dental Society, 58, 18-19.

[50] Karmarkar, S.W., Bottum, K.M. and Tischkau, S.A. (2010) Considerations for the Use of Anesthetics in Neurotoxicity Studies. Comparative Medicine, 60, 256-262.

[51] Schonherr, M.E., Hollmann, M.W. and Graf, B. (2004) [Nitrous Oxide. Sense or Nonsense for Today's Anaesthesia]. Anaesthesist, 53, 796-812. https://doi.org/10.1007/s00101-004-0742-9

[52] Department of Health and Human Services (2007) Waste Anesthetic Gases: Occupational Hazards in Hospitals. Report No. 2007-151, National Institute for Occupational Safety and Health, September 2007. 
[53] United States Dept of Labor Occupational Safety and Health Administration (2002) Occupational and Safety and Health Guideline for Nitrous Oxide: United States Dept of Labor Occupational Safety and Health Administration (cited 2010 10th November).

[54] Waugaman, W.R. and Foster, S.D. (1992) Principles and Practices of Nurse Anesthesia. 2nd Editon, Appleton \& Lange, Norwalk, Connecticut.

[55] Donaldson, D. and Meechan, J. (1995) The Hazards of Chronic Exposure to Nitrous Oxide: An Update. British Dental Journal, 178, 95-100.

[56] Henry, R.J. (1992) Assessing Environmental Health Concerns Associated with Nitrous Oxide. The Journal of the American Dental Association, 123, 41-47. https://doi.org/10.14219/jada.archive.1992.0319

[57] National Institute for Occupational Safety and Health (1988) Guidelines for Protecting the Safety and Health of Health Care Workers. Centers for Disease Control and Prevention, 88-119.

[58] American Society for Testing and Materials (1991) Standard Specification for Anesthesia Equipment: Scavenging Systems for Anesthetic Gases. Document F, West Conshohocken, PA.

[59] Schumann, D. (1989) Nitrous Oxide Anaesthesia: Risks to Health Personnel. International Nursing Review, 37, 214-217.

[60] Ryan, S.M. and Nielsen, C.J. (2010) Global Warming Potential of Inhaled Anesthetics: Application to Clinical Use. Anesthesia and Analgesia, 111, 92-98.

[61] Dale, O. and Husum, B. (1992) Nitrous Oxide: At Threat to Personnel and Global Environment? Acta Anaesthesiologica Scandinavica, 38, 777-779. https://doi.org/10.1111/j.1399-6576.1994.tb04005.x 
Appendix: Questionnaire Knowledge of Anaesthesia Providers on Exposure to Inhalational anaesthetic Agents

\section{Demographic Data}

1) Anaesthesia Provider: Anaesthesiologist [ ] Nurse Anaesthetist [ ]

2) Gender: Male [ ] Female [ ]

3) Number of years of practice as an Anaesthetist?

Less than 5 years [ ] 5 - 10 years [ ]More than 10 years [ ]

\section{Use of Inhalational Anaesthetics}

4) Do you use inhalational anaesthetics in your practice?

Yes [ ] No [ ]
5) If yes, which type(s)?
Halothane [ ] Isoflurane [ ] Desflurane [ ]
Sevoflurane [ ]

6) Do you use Nitrous Oxide in your practice?

Yes [ ] No [ ]

Perception of Exposure to Inhalational Anaesthetics

7) Do you feel exposed to inhalational anaesthetics at your workplace?

Yes [ ] No [ ]

If yes, why?

If no, why?

8) Is there an allowable limit to the concentration of inhaled anaesthetic agents in the theatre environment? Yes [ ] No [ ]

\section{Knowledge on Effects of Exposure}

9) What are the symptoms related to chronic exposure of inhaled anaesthetics? 
10) What are the major organ effects of chronic exposure to inhaled anaesthetics?

\section{Knowledge on Strategies to Reduce Exposure to Inhaled Anaesthetics}

11) Are the concentrations of inhaled anaesthetic agents routinely monitored in your working environment?

Yes [ ] No [ ]

12) Do you make any attempt(s) to reduce your exposure to inhaled anaesthetics?

Yes [ ] No [ ]

If yes, what strategies are you adopting to reduce your exposure to inhaled anaesthetics?

If no, why? 
Submit or recommend next manuscript to SCIRP and we will provide best service for you:

Accepting pre-submission inquiries through Email, Facebook, LinkedIn, Twitter, etc. A wide selection of journals (inclusive of 9 subjects, more than 200 journals)

Providing 24-hour high-quality service

User-friendly online submission system

Fair and swift peer-review system

Efficient typesetting and proofreading procedure

Display of the result of downloads and visits, as well as the number of cited articles Maximum dissemination of your research work

Submit your manuscript at: http://papersubmission.scirp.org/

Or contact jbm@scirp.org 